\title{
Estimation of Weight and Lipid Composition in Preimplantation Embryos from Jersey and Beef Breeds of Cattle
}

\author{
Julie D. Weathers ${ }^{1}$, Samuel D. Prien ${ }^{1,2^{*}}$ \\ ${ }^{1}$ Department of Animal and Food Sciences, Texas Tech University, Lubbock, TX, USA \\ ${ }^{2}$ Department of Obstetrics and Gynecology, Texas Tech University Health Sciences Center, Lubbock, TX, USA \\ Email: :Samuel.prien@ttuhsc.edu
}

Received 25 September 2014; revised 27 October 2014; accepted 4 November 2014

Copyright @ 2014 by authors and Scientific Research Publishing Inc.

This work is licensed under the Creative Commons Attribution International License (CC BY).

http://creativecommons.org/licenses/by/4.0/

(c) (i) Open Access

\begin{abstract}
Cryopreservation is the main functional means for storage of excess embryos produced from artificial reproductive technologies; the process assumes embryos chemical nature is highly conserved across embryos of the same species. However, in practice there appears to be a high degree of variability in embryo tolerance to cryopreservation, suggesting potential differences in embryo chemistry. The objective of the current study was to develop reproducible means of estimating relative embryos weight and associating those weights to lipid content. Relative embryo weights of frozen/thawed in-vivo Jersey and Crossbred beef breed embryos were determined using a modified specific gravity chamber. Embryo weights were then correlated with lipid content. Results suggest that beef cattle embryos are $20 \%-27 \%$ heavier than Jersey embryos $(P<0.001)$. Electron microscopy (EM) data suggest that these differences are due to divergent lipid content; Jersey embryos having approximately $36 \%$ lipid as compared to $8 \%$ in beef cattle embryos $(\mathrm{P}<$ 0.01); explaining the Jersey embryos lighter weight.
\end{abstract}

\section{Keywords}

Estimated Weight, Embryo, Cryopreservation, Cattle

\section{Introduction}

The first successful cryopreservation of a preimplantation embryo was performed in 1972 when the embryo was cooled to $-80^{\circ} \mathrm{C}$ at 1 degree/minute and then submerged in liquid nitrogen [1]. Cryopreservation remains the

\footnotetext{
*Corresponding author.
}

How to cite this paper: Weathers, J.D. and Prien, S.D. (2014) Estimation of Weight and Lipid Composition in Preimplantation Embryos from Jersey and Beef Breeds of Cattle. Open Journal of Veterinary Medicine, 4, 261-266.

http://dx.doi.org/10.4236/ojvm.2014.411031 
main means of storing embryos and has become standard practice in reproductive industries, primarily human and bovine. While cattle breeds such as, Angus, Simmental, Herefords and others survive current cryopreservation techniques with conception rates approaching $60 \%$ to $70 \%$, cryopreserved Jersey cattle embryos produce conceptions at a rate of approximately $20 \%$, very similar to that of the human species [2] [3].

At the whole body level, the main defining characteristic of Jersey cattle is their genetic predisposition to produce more butterfat than other bovine breeds, indicating that their cellular biochemical makeup includes more lipid content than other bovine species [4]-[7]. It has been suggested that the low conception rates in Jersey cattle are associated with embryo intracellular lipids, which have been linked to cell damage during cryopreservation [1] [4] [8] [9]. Presence of intracellular lipids in bovine oocytes and embryos has been shown to account, at least partially, for the low post thaw recovery rate [4] [9]-[11]. However, these differences in embryo lipid content have not been quantified between different bovine breeds or across species [2] [11]-[13]. Access to this quantification of lipid content could alter the way that cryopreservation methods are applied [4] [12]-[15]; particularly with mammals that possess cells with known higher lipid content (i.e. humans with higher Body Mass Index) [15]. Determination of specific gravity has been a common way to estimate lipid content in live individuals [16] [17] and foodstuffs [18]. Using this method as a format the current study aims to develop a reproducible means of estimating relative embryos weight and then relating those weights to determine lipid content. Alteration of the cryopreservation technique could allow for greater success rates in both freezing and thawing of highlipid species or certain breeds within that species.

The objective of the current study was to develop reproducible means of estimating relative embryos weight and then relate those weights to lipid content. The cryopreservation process assumes that water is highly conserved across embryos of the same species. Therefore, any dramatic shift in the embryos' chemical nature might lead to failure of the cryopreservation process. Using techniques developed in this laboratory, embryo estimated weight and lipid content were compared between Jersey cattle and beef cattle breeds.

\section{Materials and Methods}

All embryos used in the experiments were in-vivo, day-six compacted blastocysts and were donated from commercial sources. The beef cattle embryos were obtained from the Trans-Ova Genetics Satellite Center (Abernathy, TX). The Jersey cattle embryos were obtained from the US Jersey, American Jersey Association (Reynoldsburg, $\mathrm{OH}$ ). Frozen in-vivo embryos were utilized due to the limitations of the Jersey cattle industry obtaining fresh embryos, which were very much in demand during the experiment. All embryos had previously been frozen using traditional slow freeze protocols using ethylene glycol, a traditional cryoprotectant. Embryos were then thawed according to industry standards. Fifty Jersey and 50 beef cattle embryos were transferred one at a time to the experimental specific gravity apparatus.

\subsection{Specific Gravity}

As previously stated, specific gravity has been a common way to estimate lipid content in live individuals [16] [17] and foodstuffs [18]. A modified specific gravity chamber was constructed that allowed the visualization of embryos and a standard bead which was embryo shaped and of known weight, as they "dropped" a predetermined distance. The chamber was constructed of a $0.5 \mathrm{~mL}$ semen straw (Cryo Bio System; Paris, France). A distance of $1.00 \mathrm{~cm}$ was marked on the straw. Prior to experimentation, the straw was rinsed with human serum albumin (HSA) (Irvine Scientific, Santa Ana, CA), to coat the inside of the straw, to prevent embryos from "sticking" or being drawn by electrical charge to the sides of the straw. Following coating with HSA, the straw was filled with one of two medias of known specific gravity: 1) P-1 holding medium, or 2) F-2 freezing medium (Irvine Scientific, Santa Ana, CA). These mediums were chosen to prevent the media itself from potentially damaging the embryo during the process, which would allow utilization for future breeding purposes if desired. Additionally, two mediums were used in order to verify the results ensuring that the specific gravity differences seen were true variation between breed types.

The straw containing media was attached vertically to a standard ring stand and illuminated. The drop region of the straw was visualized with a Nikon SMZ2 (Nikon Inc., New York, NY) attached to an articulated arm boom microscope stand (American Optical Scientific Industries, Southbridge, MA). Embryos and standards were released at the top of the straw and the descent was timed using a stopwatch and recorded out to the tenth of one second for all procedures. Care was taken to "place" the embryo on top of the column without inducing 
any downward movement. Resulting times were then entered into the appropriate equation to estimate the embryos' weight. This process was repeated using 50 additional embryos of each breed in both the P-1 and F-2 media and the resulting data entered into that equation to confirm the approximate weights.

\subsection{Lipid Quantification}

Ten embryos of each breed were used $(n=20)$ were used in the EM studies. A small amount of Acidic Tyrode's Solution (Irvine Scientific, Santa Ana, CA) was added and allowed to sit until most of the zonapellucida was removed enzymatically. Then HSA was added in equal amounts to that of the P-1 and Tyrode's to stop the enzymatic degradation process. The embryo was then transferred to a gluteraldehyde solution, 3\% paraforinaldehyde and $1.5 \%$ gluteraldehyde. The embryos were held in the gluteraldehyde for a minimum of 24 hours to ensure complete fixation. Following fixation, embryos were then transferred to the Electron Microscopy Center at the Texas Tech University Health Sciences Center (Lubbock, TX) where they were further processed for transmission electron microscopy using standard techniques. Random sections of each embryo were observed and photographed on a Hitachi H-7650 TEM by a trained microscopist.

All resulting EM work was placed on a computerized grid from Adobe Photoshop CS2 (Adobe Acrobat, San Jose, CA). The grid places $2 \times 2 \mathrm{~cm}^{2}$ uniformly over the digital image. The squares were then qualified as either lipid containing or lipid non-containing by a single observer. A square containing more than $50 \%$ lipid was scored as lipid containing. In order to be included in the total value counted in the lipid quantification a square had to be at least $50 \%$ occupied by a cellular image. To calculate lipid content in the embryo, the lipid-containing squares were divided by total squares and multiplied by 100 to give a percentage of lipid found in the embryo section. All EM images were counted and then matched so that only those with corresponding magnifications in the opposite breed were included in the results. If multiple images at a given magnification were present, the ones with the greatest lipid content percentage present were used.

\section{Statistical Analysis}

Following data collection, descriptive statistics were performed for each set of data and an intra-assay CV established between the various standard curves to determine precision. Breed differences in lipid content were determined using student's T-test. All statistical comparisons were made using the Statistical Package for the Social Sciences (SPSS ver 12: Chicago, IL).

\section{Results}

As expected, the relationship between weight (density) and time of descent was not linear but curvilinear on a logarithmic scale (see Figure 1).

Using the two points established by the bead type; borosilicate (BS) or barium titanate (BT), points for zero time and zero weight were extrapolated mathematically resulting in four similar equations for the slope of the curves:

$$
\begin{aligned}
& \mathrm{BS} / \mathrm{P}-1 ;\left(\mathrm{y}=-0.40 \ln (\mathrm{x})+2.070, \mathrm{R}^{2}=0.987\right) ; \\
& \mathrm{BS} / \mathrm{F}-2 ;\left(\mathrm{y}=-0.40 \ln (\mathrm{x})+2.449, \mathrm{R}^{2}=0.986\right) ; \\
& \mathrm{BT} / \mathrm{P}-1 ;\left(\mathrm{y}=-0.27 \ln (\mathrm{x})+1.353, \mathrm{R}^{2}=0.993\right) ; \\
& \text { BT/F-2; }\left(\mathrm{y}=-0.22 \ln (\mathrm{x})+1.494, \mathrm{R}^{2}=0.983\right)
\end{aligned}
$$

Mathematical comparison of the results indicated the four curves established using the borosilicate (BS) or barium titanate (BT); were within $7 \%$ of each other and the $< \pm 11 \%$ of the mean weight supplied by the manufacturer. Further, while there was observable variation in the zonapellucida thickness between embryos, the variation in the time of descent between embryos within the breeds appeared normally distributed around the mean and negligible in accounting for the variation observed between the breeds $(42.4+1.1 \mathrm{~s}$ vs. $58.2+2.3 \mathrm{~s}$ in P-1 media and $173.6+4.5$ s vs. $214.5+8.8$ s in F-2 media for beef vs. Jersey embryos respectively \pm S.E.M.).

Using embryodescent times and the previously established standard curves, estimated weights were established for the embryos of between 0.2 and $0.5 \mu \mathrm{g}$. The average weight for beef cattle embryos being $0.40 \pm 0.11$ $\mu \mathrm{g} / \mathrm{mL}(\mathrm{P}<0.001)$ and Jersey breeds $0.32 \pm 0.11 \mu \mathrm{g} / \mathrm{mL}(\mathrm{P}<0.001)$ (Figure 2); to the authors' knowledge the first true estimation of embryo weight. Demonstrating Jersey cattle embryos being, on average, $21.3 \%$ times lighter than beef embryos at the same stage of development. 


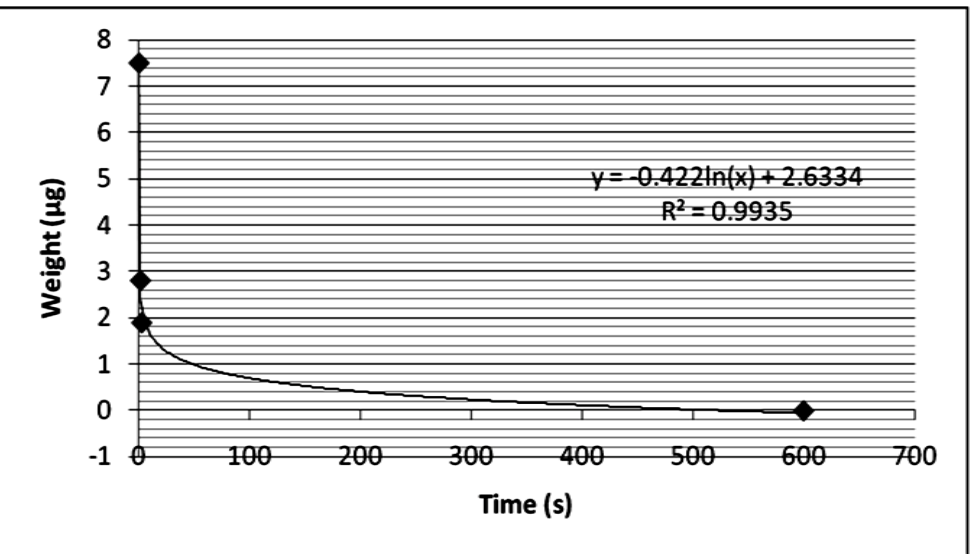

Figure 1. Representative curve of curvilinear descent of standardized beads creating a mathematically extrapolated zero time and zero weight points for use in creation of a standard curve to determine embryo weights through use of a unique specific gravity technique.

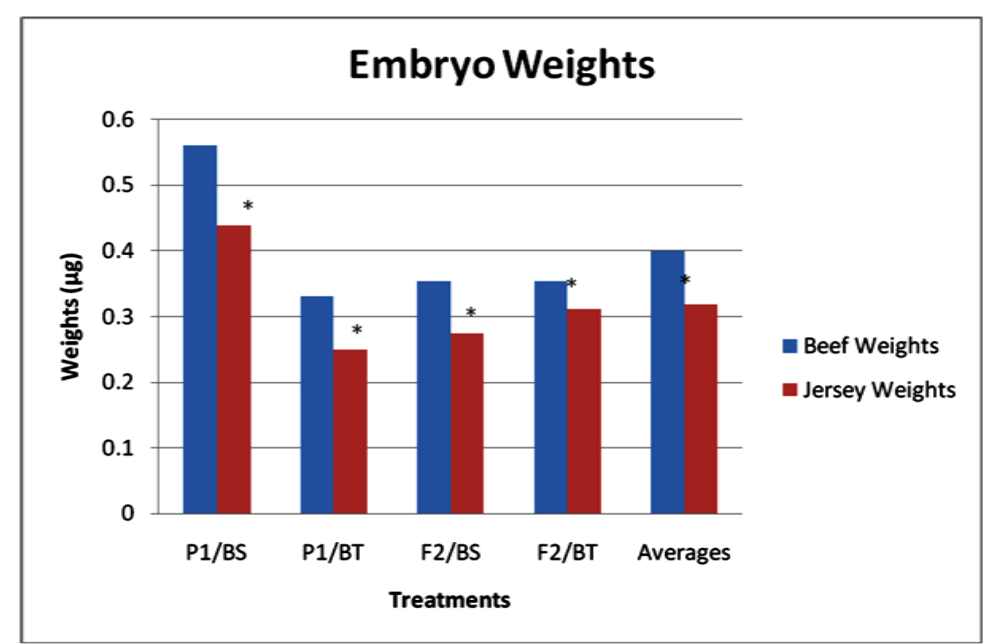

Figure 2. Determination of breed differences in embryo weight $(\mathrm{P}<0.001)$ between Jersey and beef cattle breeds as determined by a unique modified specific gravity technique.

The electron microscopy data suggest that Jersey cattle embryos $(55.2 \% \pm 22.0 \%)$ contained significantly more lipid; $(\mathrm{P}<0.001)$ than beef cattle embryos at the sample stage of development $(6.0 \% \pm 6.8 \%)$ (see Figure 3).

\section{Conclusions}

Low pregnancy rates are suggested to be associated with intracellular lipids of the embryo, which have been linked to cell damage during cryopreservation [1] [8]. These intracellular lipids in bovine oocytes and embryos have been shown to account, at least partially, for the low post thaw success rate in both in-vivo and in-vitro derived embryos [10] [19]; however, embryo lipid content has not yet been quantified.

Data from this study suggests that there is considerably more lipid content found in Jersey breed embryos. Differences can be seen both in the weight through a modified specific gravity technique, comparing Jersey to beef cattle breeds, and in the lipid quantification through electron microscopy allowing for the same breed comparisons. From the statistical analysis, it is evident that the Jersey embryos are considerably lighter in weight than that of the beef cattle breeds. Additionally, the statistical analysis shows that there is a considerable amount of more lipids present in Jersey cattle when quantified. Because of this, it is reasonable to infer that the lighter 


\section{Lipid Percentages in Jersey and Beef Breed Embryos}

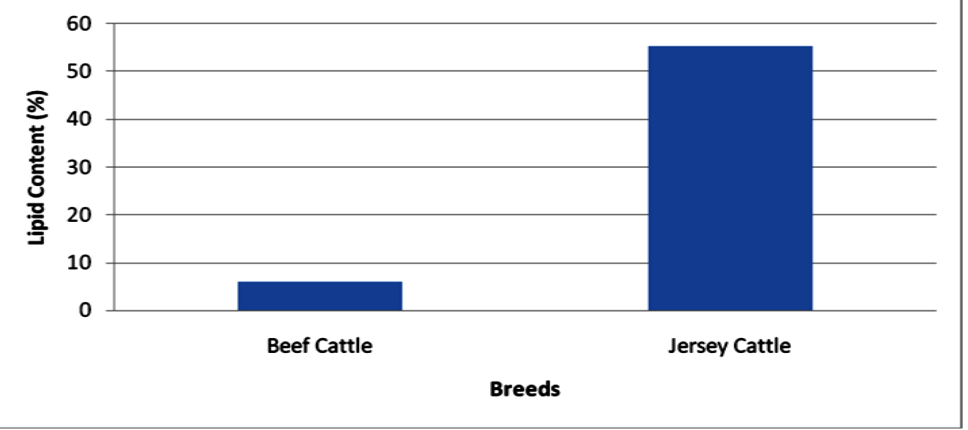

Figure 3. Determination of breed differences in embryo lipid content $(\mathrm{P}<$ 0.001 ) between Jersey and beef cattle breeds as determined by quantification of lipid content in random electron micrographs.

weight seen in the modified specific gravity technique is due solely to the excess lipid seen in the Jersey embryos.

Ongoing research in this laboratory is being conducted to compare fresh in-vivo embryos and those from various other models along with varying stages of cellular development.

\section{Acknowledgements}

Support for this work was supplied by grants from the American Jersey Association and Organon Pharmaceutical.

\section{References}

[1] Hasler, J.F. (2001) Factors Affecting Frozen and Fresh Embryo Transfer Pregnancy Rates in Cattle. Theriogenology, 56, 1401-1415.

[2] Visintin, J.A., Martins, J.F.P., Bevilacqua, E.M., et al. (2002) Cryopreservation of Bostaurus vs Bosindicus Embryos: Are They Really Different? Theriogenology, 57, 345-359.

[3] Hoffman, D.I., Zellman, G.L., Fair, C.C., et al. (2003) Cryopreserved Embryos in the United States and Their Availability for Research. Fertility and Sterility, 79, 1063-1069.

[4] Mohr, L.R. and Trounson, A.O. (1981) Structural Changes Associated with Bovine Embryos. Biology of Reproduction, 25, 1009-1025. http://dx.doi.org/10.1095/biolreprod25.5.1009

[5] Beaulieu, A.D. and Palmquist, D.L. (1995) Differential Effects of High Fat Diets on Fatty Acid Composition in Milk of Jersey and Holstein Cows. Journal of Dairy Science, 78, 1336-1344.

[6] Bitman, J., Wood, D.L., Miller, R.H., et al. (1996) Comparison of Milk and Blood Lipids in Jersey and Holstein Cows Fed Total Mixed Rations with and without Whole Cottonseed. Journal of Dairy Science, 79, 1596-1602.

[7] Karlsson, J.O.M. and Toner, M. (1996) Long Term Storage of Tissues by Cryopreservation: Critical Issues. Biomaterials, 17, 243-256. http://dx.doi.org/10.1016/0142-9612(96)85562-1

[8] Seidel, G.E. (2006) Modifying Oocytes and Embryos to Improve Their Cryopreservation. Theriogenology, 65, 228-235.

[9] Trounson, A.O., Willadsen, S.M., Rowson, L.E.A. and Necomb, R. (1976) Storage of Cow Eggs at Room Temperature and at Low Temperatures. Journal of Reproductive Fertility, 46, 173-178. http://dx.doi.org/10.1530/jrf.0.0460173

[10] Dorbrinsky, J.R. (1996) Cellular Approach to Cryopreservation of Embryos. Theriogenology, 45, 17-26.

[11] Massip, A. (2001) Cryopreservation of Embryos of Farm Animals. Reproduction of Domestic Animals, 36, 49-55. http://dx.doi.org/10.1046/j.1439-0531.2001.00248.x

[12] Steel, R. and Hasler, J.F. (2004) Pregnancy Rates Resulting from Transfer of Fresh and Frozen Holstein and Jersey Embryos. Reproduction, Fertility and Development, 16, 182-183. http://dx.doi.org/10.1071/RDv16n1Ab120

[13] Ballard, C.B. (2007) Intracellular Lipids in Bosindicus and Bos Taurus Oocytes. Louisiana State University, Baton 
Rouge.

[14] Kim, J.Y., Kinoshita, M., Ohnishi, M. and Fukui, Y. (2001) Lipid and Fatty Acid Analysis of Fresh and FrozenThawed Immature and In-Vitro Matured Bovine Oocytes. Reproduction, 122, 131-138. http://dx.doi.org/10.1530/rep.0.1220131

[15] Neimann, H. (1991) Cryopreservation of Ova and Embryos from Livestock: Current Status and Research Needs. Theriogenology, 35, 109-124.

[16] Rathbun, E.N. and Pace, N. (1945) Studies on Body Composition: The Determination of Total Body Fat by Mean of the Body Specific Gravity, Part I. The Journal of Biological Chemistry, 158, 667-676.

[17] Brown, C.J., Hillier, J.C. and Whatley, J.A. (1951) Specific Gravity as a Measure of the Fat Content of the Pork Carcass. Journal of Animal Science, 10, 97-103.

[18] Joslyn, M.A. (1970) Ash Content and Ashing Procedures. In: Joslyn, M.A., Ed., Methods in Food Analysis. Physical, Chemical and Instrumental Methods of Analysis, 2nd Edition, Academic Press, New York, 109-140.

[19] Diez, C., LeBourhis, D., Heyman, Y. and Renard, J.P. (1996) Effect of Partial Lipid Removal from in Vitro Produced Bovine Zygotes on Further Development in Vitro and on the Freezing Tolerance of Blastocysts. Theriogenology, 45, 166. http://dx.doi.org/10.1016/0093-691X(96)84639-5 
Scientific Research Publishing (SCIRP) is one of the largest Open Access journal publishers. It is currently publishing more than 200 open access, online, peer-reviewed journals covering a wide range of academic disciplines. SCIRP serves the worldwide academic communities and contributes to the progress and application of science with its publication.

Other selected journals from SCIRP are listed as below. Submit your manuscript to us via either submit@scirp.org or Online Submission Portal.
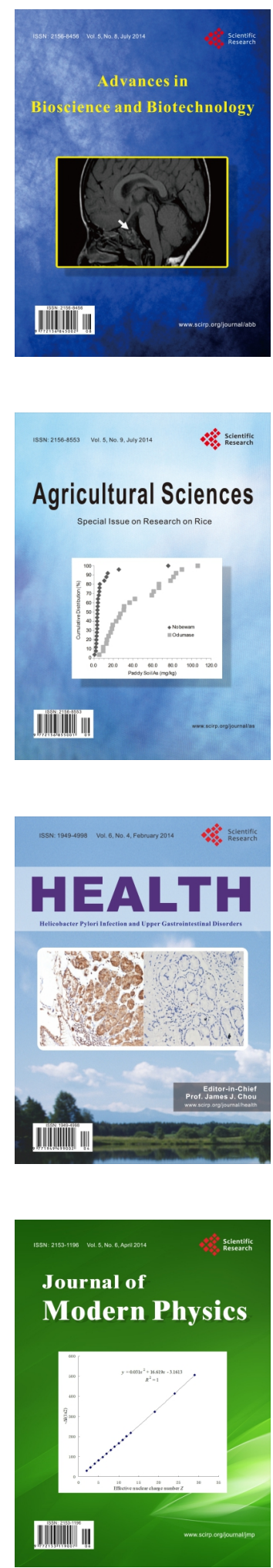
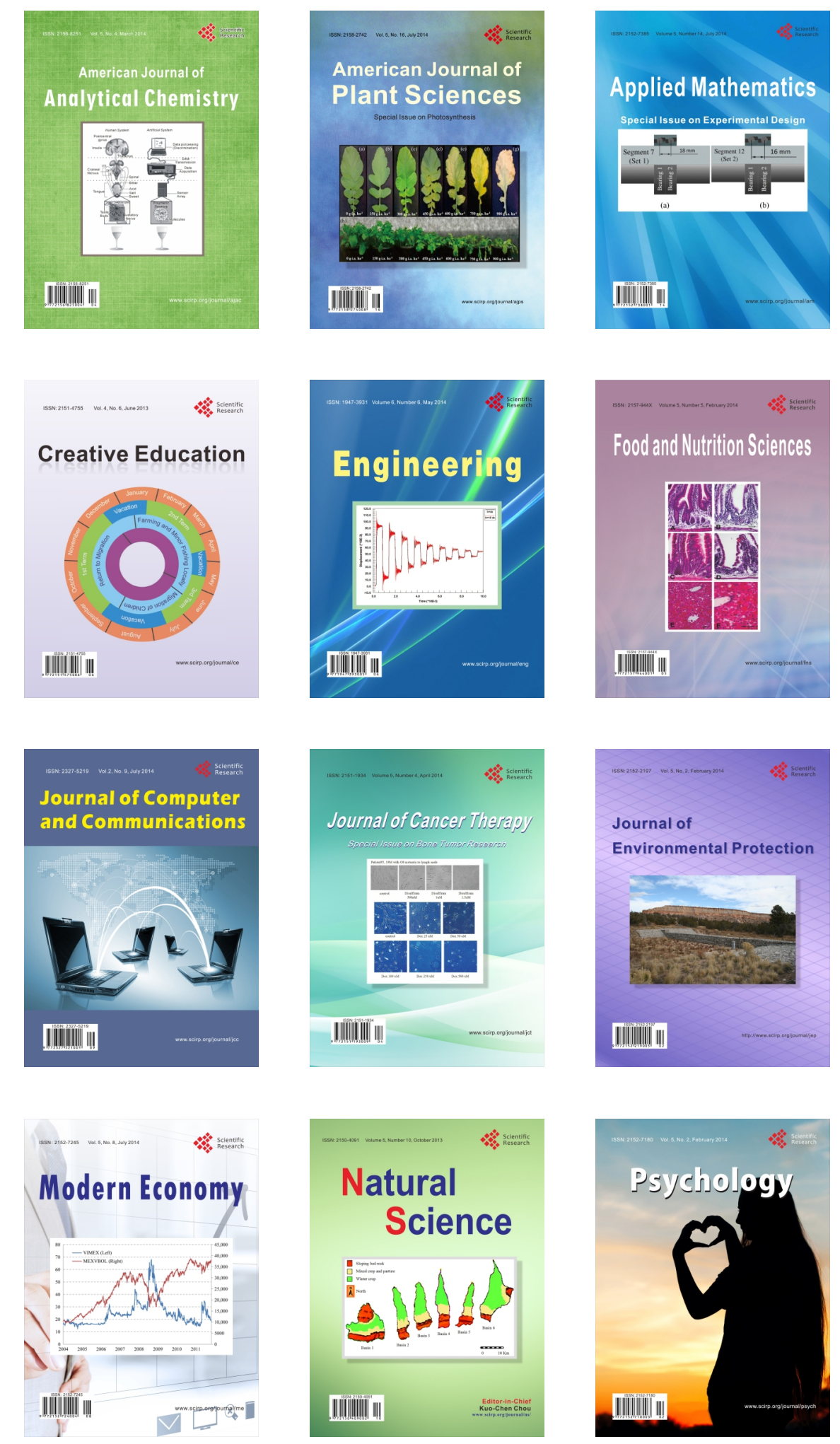